\title{
Impact Of Fintech On Bank Management And Valuation: The Case Of The Republic Of Moldova
}

\author{
Ph.D. Associate prof. Maia Pisaniuc \\ Academy of Economic Studies of Moldova (ASEM) \\ International Business Department
}

\begin{abstract}
:
Fintech has become a must have for the current financial system, and the COVD-19 pandemic has only highlighted the need for further advancements in this area. The offering of online services has grown exponentially, while on the other hand there has been an increased set of risks and opportunities both for customers, and for banks' management. Technology has paved the way both for suppliers and for customers of financial services. Mobile access of nonbanking customers, has allowed financial technology firms to capture new market segments from the unbanked population, encouraging and hence promoting financial inclusion. Fintech is one of the most captivating sectors on the global arena, having also one of the highest growth rates. It has changed the way people think about money and value exchange in real-time. The impact of Fintech on costs is also important. The downward pressure on costs due to the usage of Artificial Intelligence and Machine Learning in processing client information, the replacement of bank staff by chatbots, as well as diminishing the need for branches and physical space, represent cost items which are easy to quantify and would allow to further accelerate the business models in the banking space.

The aim of this paper is to evaluate the impact of the usage of fintech on the valuation of banks, forecast the development of the banking system in the upcoming years and assess the strategic implications on bank management, specifically in the Republic of Moldova.

Research methods: statistical analysis, forecasting, scenario analysis
\end{abstract}

Keywords: fintech, bank management, bank valuation 